\title{
PUBLIC DEBT UNDER LIMITED PRIVATE CREDIT
}

\author{
Pierre Yared \\ Columbia University
}

\begin{abstract}
There is a conventional wisdom in economics that public debt can serve as a substitute for private credit if private borrowing is limited. The purpose of this paper is to show that, while a government could in principle use such a policy to fully relax borrowing limits, this is not generally optimal. In our economy, agents invest in a short-term asset, a long-term asset, and government bonds. Agents are subject to idiosyncratic liquidity shocks prior to the maturity of the long-term asset. We show that a high public debt policy fully relaxes private borrowing limits and is suboptimal. This is because agents expecting such a policy respond by investing less than is socially optimal in the short asset which can protect them in the event of a liquidity shock. The optimal policy is more constrained and it induces a wedge between the technological rate of return on the long asset and the rate of return on bonds. In such a regime, agents subject to liquidity shocks are also borrowing constrained, and this expectation of being borrowing constrained induces them to invest the optimal level in the short asset. (JEL: H63, E62, G20)
\end{abstract}

\section{Introduction}

There is a conventional wisdom in economics that public debt can serve as a substitute for private credit if private borrowing is limited. Specifically, a government can issue public debt in order to subsidize borrowing constrained agents, and it can guarantee this public debt with future government revenues. ${ }^{1}$ The purpose of this paper is to show that, while a government could in principle use such a policy aggressively to fully relax borrowing limits, this is not generally optimal. Instead, the optimal debt policy, which can achieve the efficient allocation, is more constrained and forces some agents to remain borrowing constrained.

\section{The editor in charge of this paper was Fabrizio Zilibotti.}

Acknowledgments: I am especially grateful to Marina Azzimonti and Narayana Kocherlakota for initial discussions which inspired this project. I am grateful to Daron Acemoglu, Stefania Albanesi, Marios Angeletos, V. V. Chari, Michael Golosov, Chris Sleet, Aleh Tsyvinski, Ivan Werning, Fabrizio Zilibotti, and two anonymous referees for comments.

E-mail: pyared@columbia.edu

1. See Caballero and Krishnamurthy (2006), Kocherlakota (2007, 2009), Holmstrom and Tirole (1998), and Woodford (1990) for examples of economies in which governments can relax private borrowing limits by issuing public debt. 
We build on the canonical model of financial intermediation used by Diamond and Dybvig (1983), Jacklin (1987), Allen and Gale (2004), and Farhi, Golosov, and Tsyvinski (2009). In this model, agents can invest in a short-term and long-term asset (technology). Agents are also subject to an idiosyncratic private liquidity shock prior to the maturity of the long-term asset. We introduce two new features to this model. First, we impose that private financial contracts are not enforceable, so that agents cannot pool their investments or borrow resources from one another. Second, we introduce government bonds which can be anonymously traded across agents and which are financed by uniform lump sum taxes. These two features allow us to explore the extent to which government bonds can serve as a substitute for private credit and financial intermediation when private borrowing is limited.

In this environment, higher levels of public debt effectively slacken the borrowing limit on agents subject to liquidity shocks. Specifically, the government can subsidize agents subject to liquidity shocks by raising resources via the issuance of public bonds which are purchased by the agents not subject to liquidity shocks. These bonds are eventually repaid when the government taxes all agents' proceeds from their long-term asset. Thus, for low levels of public debt, agents subject to liquidity shocks remain borrowing constrained. As the government increases the level of debt, the return on public debt rises and agents subject to liquidity shocks become less borrowing constrained. Moreover, agents reduce their initial investment in the short-term asset relative to the long term asset since they expect to be less borrowing constrained in the event of a liquidity shock. This increased investment in the long-term asset is reinforced by the expectation of higher eventual taxes to finance repayment of the public debt. Eventually, if the government increases debt sufficiently, then no agent is borrowing constrained, and the return on government bonds equals that on the long asset. In such an economy, Ricardian Equivalence (Barro 1974) holds since local changes in fiscal policy do not affect the economy which perfectly replicates a market economy absent borrowing limits.

The main result of this paper is that such a policy which fully alleviates borrowing constraints is suboptimal. This is because such a policy induces agents to invest less than is socially optimal in the short asset which can protect them in the event of a liquidity shock. The best policy is more constrained and it induces a wedge between the technological rate of return on the long asset and the rate of return on bonds. In such a regime, agents subject to liquidity shocks are also borrowing constrained, and this expectation of being borrowing constrained induces them to invest the optimal level in the short term asset. In other words, a fiscal policy which leaves agents subject to liquidity shocks borrowing constrained can serve as a substitute for efficient financial intermediation.

Our result is most related to the work of Diamond and Dybvig (1983), and specifically, to the critique of the conclusions of this work made by Jacklin (1987) and its resolution in Farhi, Golosov, and Tsyvinski (2009). Diamond and Dybvig (1983) show that in a similar economy to ours, private financial intermediation can generate the efficient allocation even if liquidity shocks are unobservable. However, Jacklin (1987) shows that if — in addition to experiencing private liquidity shocks — agents can 
unobservably borrow and lend freely in private side markets, then this severely limits risk sharing. This is because arbitrage forces the interest rate to equal the technological rate of return, and this reduces risk sharing. Farhi, Golosov, and Tsyvinski (2009) argue that the imposition of a liquidity floor on intermediaries in such an environment can implement the efficient allocation. The main contribution of our paper to this literature is to show that efficiency can be preserved even in the presence of side trading and in the absence of financial intermediaries through the use of a simple fiscal policy with lump sum taxes and public debt. More specifically, our environment differs from previous work in that we assume that there are no intermediaries since private contracts are not enforceable. However, it is similar to Jacklin (1987) in that agents can privately trade in the market for bonds, though this is subject to a nonnegativity constraint on their government bond holdings. Therefore, in contrast to Diamond (1997)—who assumes that participation in side markets is exogenous - side trading in our environment is endogenous to the supply of government bonds.

Our result is more generally related to a broader insight present in the work of Geanakoplos and Polemarchakis (1986), Golosov and Tsyvinski (2007), and Ales and Maziero (2009). They show that absent government policy, economies with private information and anonymous trading are inefficient, and such an inefficiency can potentially be reduced by the introduction policies which induce an intertemporal wedge. ${ }^{2}$ In our environment, the presence of private borrowing limits implies that the government can utilize fiscal policy so as to let these borrowing limits bind and induce an intertemporal wedge which enhances the efficiency of investment. ${ }^{3}$

The paper proceeds as follows. Section 2 describes the model. Section 3 describes our main result. Section 4 concludes and the Appendix includes all of the proofs.

\section{Model}

\subsection{Technology and Preferences}

We build on the classical model of financial intermediation used by Diamond and Dybvig (1983), Jacklin (1987), Allen and Gale (2004), and Farhi, Golosov, and Tsyvinski (2009). The economy lasts three periods $t=0,1,2$. There are two assets in the economy. The short asset returns one unit of the consumption good at $t+1$ for each unit invested at $t$. Investment in the long asset is performed at $t=0$ and yields $\hat{R}>1$ units of the consumption good at $t=2$. For simplicity, liquidation of the long asset at date 1 yields a payoff of zero.

The economy is populated by a unit continuum of ex-ante identical agents. These individuals receive an endowment $e$ at $t=0$. At $t=1$, each individual draws his

2. See also Bisin and Rampini (2006), Geanakoplos and Polemarchakis (2008), and Greenwald and Stiglitz (1986) for arguments along these lines.

3. That borrowing limits can be used to implement constrained efficient allocations has also been noted in Albanesi and Sleet (2006) who consider the implementation of second-best policies in private information economies. 
type $\theta=\{0,1\}$. With probability $\pi \in(0,1)$, an individual is of type $\theta=0$, and with probability $1-\pi$, he is of type $\theta=1$. The utility of an individual of type $\theta$ is denoted by

$$
U\left(c_{1}, c_{2}, \theta\right)=(1-\theta) u\left(c_{1}\right)+\theta \rho u\left(c_{1}+c_{2}\right)
$$

where $c_{1} \geq 0$ corresponds to the agent's consumption in period $1, c_{2} \geq 0$ corresponds to the agent's consumption in period 2 , and $\rho$ is a constant. We assume that $u(\cdot)$ is twice continuously differentiable, strictly increasing, and strictly concave with $\lim _{c \rightarrow 0} u^{\prime}(c)=\infty$ and $\lim _{c \rightarrow \infty} u^{\prime}(c)=0$. In addition, as in Diamond and Dybvig (1983), we assume that the intertemporal elasticity of substitution is less than or equal to 1 ,

$$
-\frac{u^{\prime}(c)}{c u^{\prime \prime}(c)} \leq 1 \text { for all } c>0,
$$

and that $\hat{R}^{-1}<\rho<1$ so that $\rho \hat{R}>1$.

Agents of type $\theta=0$ are affected by liquidity shocks, and only value consumption in the first period whereas agents of type $\theta=1$ are unaffected by liquidity shocks and are indifferent between consumption in the first or second period. The types of agents are private and cannot be observed by other agents. We let $\alpha=\left\{c_{1}(\theta), c_{2}(\theta)\right\}_{\theta \in\{0,1\}}$ denote an allocation of consumption across consumers.

As in Farhi, Golosov, and Tsyvinski (2009), we do not impose a sequential service constraint which implies that there are no bank runs in our model. In this economy we define $L \in[0,1]$ as the fraction of the period 0 endowment which is invested in the short asset at date 0 .

\subsection{Government Policy and Markets}

The government raises lump sum taxes $\tau_{t} \gtreqless 0$ at $t=1,2 .{ }^{4}$ The government has zero initial debt and does not finance any public spending so that its dynamic budget constraints at dates 1 and 2, respectively, are

$$
\begin{aligned}
\tau_{1}+q B & =0 \text { and } \tau_{2}-B=0 \\
\text { for } B & =\pi b(0)+(1-\pi) b(1) .
\end{aligned}
$$

$b(\theta)$ denotes the government bonds purchased by an agent of type $\theta$, and $q$ corresponds to the market price of the government bonds. Let $\psi=\left\{\tau_{1}, \tau_{2}, B, q\right\}$ correspond to a government policy.

We impose that private financial contracts are not enforceable, so that agents cannot pool their investments or borrow resources from one another. This allows us to explore the extent to which government bonds can serve as a substitute for private

4. The government cannot operate the technology available to the agents and for this reason, there is no motive for the taxation of the endowment at date 0 . 
credit and financial intermediation when private borrowing is limited. This means that public bonds cannot be shorted so that $b(\theta) \geq 0 .^{5}$ As such, the dynamic budget constraints of the agent can be written as

$$
\begin{gathered}
L \in[0,1], \\
c_{1}(\theta)=L e-\tau_{1}-q b(\theta) \text { for } \theta=\{0,1\} \\
c_{2}(\theta)=\hat{R}(1-L) e-\tau_{2}+b(\theta) \text { for } \theta=\{0,1\},
\end{gathered}
$$

where we have implicitly assumed that $q<1$ so that agents prefer to save using government bonds between $t=1$ and $t=2$ versus using the short asset. All of our results regard the parameter space for which government policy induces $q<1$ so that (5) and (6) are without loss of generality. Together with equation (3), equations (5) and (6) imply that an allocation $\alpha$ is feasible if it satisfies

$$
\pi\left[c_{1}(0)+\frac{c_{2}(0)}{\hat{R}}\right]+(1-\pi)\left[c_{1}(1)+\frac{c_{2}(1)}{\hat{R}}\right]=e .
$$

Let

$$
\gamma=\left\{L \in[0,1],\left\{c_{1}(\theta) \geq 0, c_{2}(\theta) \geq 0, b(\theta) \geq 0\right\}_{\theta=\{0,1\}}\right\}
$$

represent the market choices of the agent. The agent's problem can be written as

$$
\max _{\gamma} \pi u\left(c_{1}(0)\right)+(1-\pi) \rho u\left(c_{1}(1)+c_{2}(1)\right)
$$

subj. to: equations (4)-(6).

We can now define a competitive equilibrium.

DEFINITION 1. A competitive equilibrium is an agent's market choices $\gamma$, a government policy $\psi$, and an allocation $\alpha$, such that

1. $\gamma$ solves the agent's problem (8),

2. $\psi$ satisfies the government budget constraint (3), and

3. $\alpha$ satisfies the resource constraint (7).

Define $\Lambda$ as the set of allocations $\alpha$ which are generated under a competitive equilibrium. To get a sense of the set $\Lambda$, note that we can substitute equation (3) into (5) and (6) so as to rewrite the agent's problem in this economy as

$$
\max _{\gamma} \pi u\left(c_{1}(0)\right)+(1-\pi) \rho u\left(c_{1}(1)+c_{2}(1)\right)
$$

5. We can easily allow for partial enforceability of private lending contracts, and all of our results continue to hold for any finite $\bar{d}$ which represents the borrowing limit of agents. This is because in such an environment the return on private and public bonds are equal and the government can freely manipulate $B$ so that any finite debt limit $\bar{d}$ eventually binds. 


$$
\begin{gathered}
\text { subj. to : } \quad c_{1}(\theta)+q c_{2}(\theta)=L e+q \hat{R}(1-L) e \quad \text { for } \theta=\{0,1\}, \text { and } \\
B \geq \hat{R}(1-L) e-c_{2}(\theta) \quad \text { for } \theta=\{0,1\} .
\end{gathered}
$$

This substitution shows that the solution to the agent's problem in our economy is equivalent to the solution to his problem in an economy without government policy in which he trades private claims and is subject to an exogenous borrowing limit $B$. This observation reflects the more general result in Theorem 1 of Kocherlakota (2007) who shows the equivalence between a private and public bond economy. More specifically, in choosing the level of public debt $B$, the government effectively chooses the tightness of (11). Since in equilibrium it is going to be the agents subject to liquidity shocks who borrow, the level of $B$ thus determines the extent to which these agents are borrowing constrained.

\section{Analysis}

\subsection{Efficient Allocation}

As a benchmark, it is useful to characterize the efficient allocation. This allocation solves the following problem:

$$
\begin{aligned}
& \max _{\alpha} \pi u\left(c_{1}(0)\right)+(1-\pi) \rho u\left(c_{1}(1)+c_{2}(1)\right) \\
& \text { subj.to : } \quad \text { (7). }
\end{aligned}
$$

The below lemma describes the solution to this problem using the superscript $E$.

LEMmA 1(Efficient Allocation). The solution to (12) satisfies $e<c_{1}^{E}(0)<c_{2}^{E}(0)<$ $\hat{R} e$ and $c_{2}^{E}(0)=c_{1}^{E}(1)=0$ with

$$
u^{\prime}\left(c_{1}^{E}(0)\right)=\rho \hat{R} u^{\prime}\left(c_{2}^{E}(1)\right) .
$$

In the efficient allocation, agents subject to liquidity shocks only consume at $t=1$ and agents not subject to liquidity shocks consume at $t=2$. Moreover, (13) implies that the marginal rate of substitution between $t=1$ and $t=2$ consumption is below the technological rate of return $\hat{R}$ since $\rho<1$.

\subsection{Competitive Equilibrium}

As already discussed, in this economy private financial contracts are not enforceable, though the setup of the agent's problem in equations (9)-(11) shows that the presence of government bonds means that they can serve as a substitute for private financial markets. Specifically, the government can choose a level of debt $B$ which it effectively borrows from agents not subject to liquidity shocks on behalf of those subject to liquidity shocks. In this section, we characterize the economy under different levels of government bonds. 
3.2.1. High-Debt Policy. We first consider a situation in which the level of public debt is sufficiently high that constraint (11) does not bind in the solution to the agent's problem. Specifically, let

$$
\bar{B}=(1-\pi) \hat{R} e .
$$

The following lemma characterizes the competitive equilibrium for all $B>\bar{B}$.

LEMMA 2 (High-Debt Policy). If $B>\bar{B}$, then $q=1 / \hat{R}, c_{1}(0)=e<c_{1}^{E}(0), c_{2}(1)=$ $\hat{R} e>c_{2}^{E}(0)$, and $c_{2}(0)=c_{1}(1)=0$.

The lemma states that if the level of debt is above a threshold, then (11) stops binding, so that the allocation is identical to one in which no agent is borrowing constrained and $\hat{R}$ and $1 / q$ are equal to one another. When debt becomes sufficiently high, local changes in fiscal policy have no impact on market allocations since Ricardian Equivalence holds, and the government is effectively choosing a policy which replicates private markets in the absence of borrowing limits. Suppose for instance that $B>\bar{B}$ and that the government were to increase current taxes $\tau_{1}$ by some arbitrarily small amount $\epsilon>0$. Then agents of all types would anticipate a decrease in future taxes $\tau_{2}$ by $\epsilon / q$ (since government debt is reduced) and they would therefore decrease their savings $q b(\theta)$ uniformly by $\epsilon$, fully offsetting the increase in date 1 taxes. Such an offsetting reduction in savings is possible since all agents are purchasing government bonds. Thus, the small change in government policy has no impact on allocations and interest rates.

Note that in this economy, agents subject to liquidity shocks do not consume at date 2 and agents not subject to liquidity shocks only consume at date 2 . Agents not subject to liquidity shocks prefer to consume at date 2 since the return on government bonds exceeds 1. Agents subject to liquidity shocks only consume at date 1 because consuming at date 2 (which they do not value) is wasteful given that returns on bonds are sufficiently high. Specifically, agents prefer to avoid the possibility of wasting long assets if they are subject to the liquidity shock, and they instead hold short assets with which they purchase government bonds in the event of avoiding the liquidity shock.

Lemmas 1 and 2 imply that the economy in which no agent is borrowing constrained is inefficient. More specifically, it entails over-investment in the long asset and under-investment in the short asset relative to the efficient allocation. This result is related to the work of Jacklin (1987). He shows that in the model of Diamond and Dybvig (1983), the ability of agents to borrow and lend freely at some interest rate $1 / q$ generates arbitrage forces which push $1 / q$ to equal the technological rate of return $\hat{R}$. This reduces the level of social insurance since there is effectively less redistribution from the agents not subject to liquidity shocks to those subject to liquidity shocks. As discussed in the introduction, this insight more generally reflects the fact that in an economy with private information and anonymous trades, agents will generally be underinsured. 
3.2.2. Low-Debt Policy. We now consider how our above conclusions change if the government instead chooses a level of debt below $\bar{B}$. In this situation, $b(0)=0$ so that agents subject to liquidity shocks are borrowing constrained and constraint (11) binds. Suppose now that the government were to reduce public debt by increasing current taxes $\tau_{1}$ by some arbitrarily small amount $\epsilon>0$. In this situation, these agents subject to liquidity shocks would not be able to decrease their savings $q b(\theta)$ by $\epsilon$ so as to fully offset the increase in date 1 taxes. Therefore, local changes in the level of public debt are no longer neutral. The below lemma characterizes the equilibrium for low levels of public debt. To simplify the discussion we limit our examination to the case for which public debt $B$ is above some threshold $\hat{B}<\bar{B}$ which is defined in the Appendix. ${ }^{6}$

Lemma 3 (Low-Debt Policy). There exists some $\hat{B} \in(0, \bar{B})$ such that if $B \in(\hat{B}, \bar{B}]$, then $q=(e / B-1 / \hat{R})(1-\pi) / \pi, c_{1}(0)=(e-B / \hat{R}) / \pi, c_{2}(1)=B /(1-\pi)$, and $c_{2}(0)=c_{1}(1)=0$.

The lemma states that the price of public debt $q$ is decreasing in public debt $B$, the consumption of agents subject to liquidity shocks $c_{1}(0)$ is decreasing in public debt $B$, and the consumption of agents not subject to liquidity shocks $c_{2}(1)$ is increasing in public debt $B$.

The mechanics behind government policy are as follows. If agents are affected by a liquidity shock at date 1 , they receive a lump sum transfer from the government which they consume and they do not purchase any government bonds. They would in principle like to borrow at the same low rate as the government, but they are incapable of doing so because of private borrowing limits. If instead, agents are not subject to liquidity shocks, then they take this lump sum transfer together with their holdings of the short asset in order to purchase government bonds which yield interest $1 / q>1$ into date 2. At date 2, agents are taxed on the gross return on the long asset and on government bonds, and the government uses this revenue to finance the debt which it incurred at date 1 .

Note that the inability to borrow by agents subject to liquidity shocks sustains a wedge between the technological rate of return $\hat{R}$ and the bond rate of return $1 / q$. Moreover, this wedge declines as the level of public debt rises. This is because as the government increases its bond issuance, the rate of return on those bonds increases in order to attract financing from agents not subject to liquidity shocks. As the rate of return rises and as the level of bond issuance rises, the borrowing limit (11) on agents subject to liquidity shocks is slackened. Since agents become ex-ante less concerned about being borrowing constrained, they invest more of their resources in the long asset relative to the short asset at date 0 . This increased investment in the long asset is reinforced by the expectation of higher taxes at date 2 to finance the public debt. Therefore, as the level of public debt rises, consumption at date 1 during a liquidity shock falls and consumption at date 2 in the absence of a liquidity shock rises. ${ }^{7}$

6. Above this threshold it is the case that $q<1$ so that constraints (5) and (6) apply.

7. If instead $B<\hat{B}$, then the return on government bonds becomes so low that agents may be willing to invest a sufficient amount in the long asset that they waste resources at date 2 in the event that they receive 


\subsection{Optimal-Debt Policy}

We have shown that a high-debt policy with $B \geq \bar{B}$ does not coincide with the efficient outcome since agents invest too little of their initial endowment in the short asset. We have also shown that for levels of public debt $B$ below $\bar{B}$, agents respond to reductions in $B$ by investing more resources in the short asset. We now consider the optimal fiscal policy which solves the following program:

$$
\begin{aligned}
\max _{\alpha} & \pi u\left(c_{1}(0)\right)+(1-\pi) \rho u\left(c_{1}(1)+c_{2}(1)\right) \\
\text { subj.to : } & \alpha \in \Lambda,
\end{aligned}
$$

where as a reminder $\Lambda$ corresponds to the set of allocations which are sustained by a competitive equilibrium.

CONDition 1.

$$
\frac{\pi}{1-\pi}>1-\frac{1}{\hat{R}} \frac{c_{2}^{E}(1)}{c_{1}^{E}(0)}
$$

Proposition 1 (Optimal-Debt Policy). The solution to (14) admits $B<\bar{B}$ and $1 / q<\hat{R}$, and if Condition 1 holds, then it attains the efficient allocation.

This proposition is the main result of this paper. The first part of Proposition 1 states that the optimal fiscal policy lets agents subject to liquidity shocks be borrowing constrained and it admits a wedge between the rate of return on bonds and the rate of return on long assets. To see the intuition for this result, consider the allocation starting from $q=1 / \hat{R}$ and $B=\bar{B}$ where from Lemma 3, such an allocation admits $c_{1}(0)=e$ and $c_{2}(1)=\hat{R} e$. Suppose the government were to choose an alternative fiscal policy which reduces public debt by $\hat{R} \epsilon$ for $\epsilon>0$ arbitrarily small. From Lemma 3, the alternative policy admits a perturbed allocation $c_{1}^{\prime}(0)=e+\epsilon / \pi$ and $c_{2}^{\prime}(1)=\hat{R}(e-\epsilon /(1-\pi))$. The change in social welfare from this perturbation for $\epsilon$ sufficiently small has the same sign as

$$
u^{\prime}\left(c_{1}(0)\right)-\rho \hat{R} u^{\prime}\left(c_{2}(1)\right),
$$

which is positive since $\rho<1, c_{1}(0)<c_{1}^{E}(0)$, and $c_{2}(1)>c_{2}^{E}(0)$. In other words, the government can tighten the borrowing limit on agents subject to liquidity shocks which induces them to invest more in the short asset. This raises social welfare since it increases the amount of resources available at date 1 for the consumption of agents subject to liquidity shocks and this benefit outweighs the cost of reducing the date 2 consumption of agents not subject to liquidity shocks.

a liquidity shock at date 1 (i.e., $c_{2}(0)>0$ ). Under some conditions, an increase in $B$ in this region increases date 1 consumption by increasing interest rates and reducing the amount invested in the long asset. Details available upon request. 
The second part of Proposition 1 states that the optimal fiscal policy attains the efficient allocation if Condition 1 is satisfied. Condition 1 implies that if faced with the interest rate associated with the efficient allocation $c_{2}^{E}(1) / c_{1}^{E}(0)$, an agent would not invest so much in the long asset that resources are wasted at date 2 with $c_{2}(0)>0$. This condition always holds for example if $\pi>1 / 2$ or if $\hat{R}$ is sufficiently close to 1 so that the economic motive for investing in the long asset is low. Thus, if Condition 1 holds, it is not only the case that the optimal policy induces a wedge between $1 / q$ and $\hat{R}$, but it is also the case that it induces the fully efficient level of investment in the short asset. If Condition 1 does not hold, then a fiscal policy which admits a wedge between the rate of return on bonds and the rate of return on long assets raises efficiency relative to a high debt policy, though it cannot achieve the efficient allocation. ${ }^{8}$

\section{Conclusion}

We have introduced fiscal policy to a classical model of financial intermediation to argue that it is not generally optimal for the government to use fiscal policy to relax all private borrowing limits. Our result emerges from the more general principle that the presence of borrowing limits induces a wedge between the return on bonds and on technology, and that such a wedge can enhance efficiency in economies with private information and anonymous trades.

There are two additional issues to keep in mind in interpreting this result. First, there is no sense in which public debt is the unique policy tool which can improve efficiency in this environment. For example, the government could choose a proportional tax on bond returns which would achieve the same result for any quantity of debt. ${ }^{9}$ We focus on an environment in which the supply of public bonds has real effects since we are motivated by the economic argument that public bonds can relax private borrowing limits.

One can easily imagine an extension of our model in which additional instruments are necessary, particularly if the government is unable to affect the interest rate by changing the level of public bonds. For instance, suppose our environment were a small open economy in which the date 1 interest rate is fixed at $\hat{R}$ independently of fiscal policy, and the government can issue bonds abroad at date 1 . In this environment, borrowing constraints on agents do not have any effect on their allocation, since agents can always satisfy any borrowing limit by investing their entire endowment in the short asset and preserving the option to save abroad at the interest rate $\hat{R}$ in the event they avoid a liquidity shock at date 1 . Such an allocation coincides with the inefficient allocation described in Lemma 2. Therefore, if the only policy tool for the government

8. In this situation, it may be better to combine a fiscal intervention with other policies which directly limit the size of agents' long asset positions such as the liquidity floor discussed in Farhi, Golosov, and Tsyvinski (2009).

9. More generally, Bassetto and Kocherlakota (2004) show that government debt becomes irrelevant in the presence of a rich set of tax instruments. 
is to change borrowing limits via public debt and lump sum taxes, then fiscal policy has no effect on allocations which are inefficient. ${ }^{10}$ For this reason, achieving the efficient allocation actually requires additional instruments, such as distorting taxes on the savings of agents not subject to liquidity shocks so as to create better risk sharing between agents subject to and not subject to liquidity shocks.

A second issue to keep in mind is that what we describe is only one channel through which the provision of public insurance can hinder efficiency. In particular, in examining the setting of Diamond and Dybvig (1983), we focus on how the supply of public bonds at date 1 can affect the maturity structure of investments ex ante at date 0 . In doing so, we ignore how the supply of public bonds at date 1 can affect redistribution from date 1 onward conditional on the maturity structure of investment. As an example, suppose that government policy at date 0 is expected to involve $B \in(\hat{B}, \bar{B}]$, so that Lemma 3 applies. In such a setting, it can be shown that, conditional on the investment in the short asset $L$, any ex-post increase in the supply of bonds has no effect on allocations or interest rate, since agents anticipate higher taxes at date 2 and respond by increasing savings at date 1 one for one. ${ }^{11}$ Alternatively, any ex-post decrease in the supply of bonds reduces interest rates proportionately, has no impact on the welfare of agents subject to liquidity shocks, and strictly decreases the welfare of agents not subject to liquidity shocks. This is because conditional on $L$, the total amount saved by agents not subject to liquidity shocks to finance the government at date 1 does not respond to reductions in the interest rate, and this follows from our assumption on preferences in (1). Therefore, there is no scope for redistribution ex post. If instead preferences were replaced with $\theta u\left(c_{1}\right)+(1-\theta) u\left(c_{2}\right)$ with types $\theta \in(0,1)$ so that all agents value consumption at both dates, then fiscal policy affects social welfare even conditional on the level of investment $L$. This is because the level of savings of agents not subject to liquidity shocks responds to the interest rate. ${ }^{12}$ How this concern for ex-post redistribution interacts with the optimal provision of ex-ante incentives for investment is an interesting area for future research.

A final issue to keep in mind is that there are many other ways in which the provision of public insurance can hinder efficiency. In an alternative setting, for instance, Attanasio and Rios-Rull (2000) show that public insurance can interfere with incentives to repay. One can also consider additional factors not studied here such as a government's incentive to default or political economy constraints which could hinder a government's ability to provide public insurance efficiently.

10. Note that this conclusion depends on the rate of return abroad being equal to $\hat{R}$. If it were below $\hat{R}$, then fiscal policy would cease to be neutral for intermediate levels of government bonds.

11. If agents not subject to liquidity shocks did not increase their savings, they would violate the constraint that $c_{2}(0) \geq 0$.

12. More specifically, it can be shown that holding $L$ fixed, a reduction in the level of public debt starting from a point at which borrowing constraints do not bind can serve as a means of redistributing away from savers towards borrowers, since such a reduction in debt reduces the interest payment on that debt. Details of some preliminary analysis of this question is available upon request. 


\section{Appendix}

\section{Proof of Lemma 1}

$c_{2}(0)>0$ cannot be optimal since agents of type 0 do not value consumption at date 2 . If it were the case that $c_{1}(1)>0$ then one could decrease $c_{1}(1)$ by some $\epsilon>0$ arbitrarily small while increasing $c_{2}(1)$ by $\epsilon \hat{R}$ which satisfies equation (7) and which strictly increases welfare. This establishes $c_{2}(0)=c_{1}(1)=0$. Equation (13) follows from the first-order conditions with respect to $c_{1}^{E}(0)$ and $c_{2}^{E}(1)$. Equation (13) implies that $c_{1}^{E}(0)<c_{2}^{E}(1)$ since $\rho \hat{R}>1$. Note that equation (2) implies that

$$
d \log u^{\prime}(c) / d \log c=x u^{\prime \prime}(x) / u^{\prime}(c) \leq-1 .
$$

Therefore, since $\rho \hat{R}>1$ then (13) implies that since $c_{2}^{E}(1)>c_{1}^{E}(0)$ it must be that

$$
u^{\prime}\left(c_{1}^{E}(0)\right) \geq u^{\prime}\left(c_{2}^{E}(1)\right) \frac{c_{2}^{E}(1)}{c_{1}^{E}(0)} .
$$

Equation (A.1) together with (13) implies that $c_{2}^{E}(1) \leq \rho \hat{R} c_{1}^{E}(0)$, which combined with (7) implies that $c_{1}^{E}(0)>e$ and $c_{2}^{E}(1)<\hat{R} e$.

\section{Proof of Lemmas 2 and 3}

Step 1. Let us define $\hat{B}$ as

$$
\hat{B}=\max \left\{e\left(\frac{\pi}{1-\pi}+\frac{1}{\hat{R}}\right)^{-1}, \tilde{B}\right\}
$$

for $\tilde{B} \in(0, \bar{B})$ which solves

$$
\pi u^{\prime}\left(\frac{e-\tilde{B} / \hat{R}}{\pi}\right)-(1-\pi) \rho\left(\hat{R}-\left(\frac{\tilde{B}}{e-\tilde{B} / \hat{R}}\right)\left(\frac{\pi}{1-\pi}\right)\right) u^{\prime}\left(\frac{\tilde{B}}{1-\pi}\right)=0 .
$$

This solution exists since the left-hand side of (A.3) equals $-\infty$ if $\tilde{B}=0$ and equals $\pi u^{\prime}(e)$ if $\tilde{B}=\bar{B}$. Moreover, it is straightforward to see that the left-hand side of (A.3) is monotonically increasing in $\tilde{B}$ so that $\tilde{B}$ is uniquely defined.

Step 2. Since it is possible that agents invest in the short asset between $t=1$ and $t=2$, equations (5) and (6) in the full problem must be replaced with

$$
\begin{aligned}
& c_{1}(\theta)=L e-\tau_{1}-q b(\theta)-s(\theta) \text { for } \theta=\{0,1\}, \quad \text { and } \\
& c_{2}(\theta)=\hat{R}(1-L) e-\tau_{2}+b(\theta)+s(\theta) \text { for } \theta=\{0,1\},
\end{aligned}
$$

where $s(\theta) \geq 0$ represents the amount invested in the short asset for an agent of type $\theta$ between $t=1$ and $t=2$. Equations (3), (A.4), and (A.5) imply that (7) in the full problem must be replaced with

$$
\pi\left[c_{1}(0)+\frac{c_{2}(0)}{\hat{R}}\right]+(1-\pi)\left[c_{1}(1)+\frac{c_{2}(1)}{\hat{R}}\right] \leq e,
$$

which binds if $s(\theta)=0$ for $\theta=\{0,1\}$. 
Step 3. We can simplify the agent's problem into a choice of $L$ conditional on a level of $B$ and $q$. We can show that the agent's choice of $L$ must solve

$$
\max _{L \in[0,1]}\{\pi u(L e+q(B-\max \{B-\hat{R}(1-L) e, 0\}))+(1-\pi) \rho u(\hat{R}(1-L) e+L e / q)\} .
$$

To establish this, first note that $q \leq 1$. If instead $q>1$, then $b(\theta)=0$ for $\theta=\{0,1\}$, since the agent could otherwise make himself strictly better off by reducing $q b(\theta)$ by $\epsilon>0$ arbitrarily small, increasing $s(\theta)$ by $\epsilon / q$, and increasing $c_{1}(\theta)$ by $\epsilon(1-1 / q)$. However, if $b(\theta)=0$ for $\theta=\{0,1\}$, this violates (3) since $B \geq \hat{B}>0$.

Let us now prove that (A.7) holds if $q<1$. Optimality requires $s(\theta)=0$, since the agent could otherwise make himself strictly better off by increasing $q b(\theta)$ by $\epsilon>0$ arbitrarily small, decreasing $s(\theta)$ by $\epsilon / q$, and increasing $c_{1}(\theta)$ by $\epsilon(1 / q-1)$. Moreover, $c_{1}(1)=0$ since an agent not subject to liquidity shocks could otherwise make himself strictly better off by reducing $c_{1}(1)$ by $\epsilon>0$ arbitrarily small, increasing $q b(1)$ by $\epsilon$, and increasing $c_{2}(1)$ by $\epsilon / q$. Therefore from (A.4) for $\theta=1$,

$$
b(1)=\left(L e-\tau_{1}\right) / q=L e / q+B,
$$

where we have substituted in for $\tau_{1}$ using (3). Moreover, since $b(0)$ and $c_{2}(0)$ cannot be negative, and since it is optimal to minimize $c_{2}(0)$ given that it does not increase welfare, it must be that from (A.5) for $\theta=0$ that

$$
b(0)=\max \left\{\tau_{2}-\hat{R}(1-L) e, 0\right\}=\max \{B-\hat{R}(1-L) e, 0\},
$$

where we have substituted in for $\tau_{2}$ using equation (3). Substituting (3), (A.8), and (A.9) into (A.4) and (A.5), we can write the agent's problem (8) as (A.7).

Now suppose that $q=1$. From (A.4) and (A.5), this implies from (A.4) for $\theta=1$ that

$$
c_{1}(1)+c_{2}(1)=L e+\hat{R}(1-L) e,
$$

where we have substituted in for $\tau_{1}$ and $\tau_{2}$ using (3). Moreover, since $b(0), s(0)$, and $c_{2}(0)$ cannot be negative, and since it is optimal to minimize $c_{2}(0)$ given that it does not increase welfare, it must from (A.5) for $\theta=0$ that

$$
s(0)+b(0)=\max \left\{\tau_{2}-\hat{R}(1-L) e, 0\right\}=\max \{B-\hat{R}(1-L) e, 0\},
$$

where we have substituted in for $\tau_{2}$ using (3). Substituting (3), (A.10), and (A.11) into (A.4) and (A.5) taking into account that $q=1$, we can write the agent's problem (8) as (A.7).

Step 4. Since (A.7) characterizes $L$ conditional on $B$ and $q$, a useful simplification is to characterize the equilibrium $q$ as a function of $L$ and $B$ so as to solve for $L$ as a function of $B$ only. We now show that conditional on $L$ and $B$, if $q<1$, then $q$ must satisfy 


$$
\begin{aligned}
q & =\bar{q}(L, B)=\frac{c_{1}(0)}{c_{2}(0)+c_{2}(1)} \\
& =\frac{1}{\hat{R}}\left(\frac{L}{(1-L)-(2 \pi-1) \max \{(1-L)-B /(\hat{R} e), 0\}}\right)\left(\frac{1-\pi}{\pi}\right),
\end{aligned}
$$

where $\bar{q}(L, B)$ is increasing in $L$ for $\hat{R}(1-L) e>B$. Multiply (A.5) by $q$ and add it to (A.4) to achieve

$$
\begin{gathered}
c_{1}(0)+q c_{2}(0)=L e-\tau_{1}+q\left(\hat{R}(1-L) e-\tau_{2}\right)=L e+q \hat{R}(1-L) e, \quad \text { and } \\
q c_{2}(1)=L e-\tau_{1}+q\left(\hat{R}(1-L) e-\tau_{2}\right)=L e+q \hat{R}(1-L) e, \quad \text { A }
\end{gathered}
$$

where we have used (3) and the fact that $s(\theta)=0$ and $c_{1}(1)=0$ if $q<1$ established in step 3. Equations (A.13) and (A.14) imply the first equality in (A.12). Substitution of (A.8) into (A.4) using (3) implies that $c_{1}(0)=L e / \pi$. Substitution of (A.9) into (A.5) using (3) implies that

$$
c_{2}(0)=\max \{\hat{R}(1-L) e-B, 0\} .
$$

Therefore, from (A.6) which binds this implies that

$$
c_{2}(0)+c_{2}(1)=\frac{\hat{R}(1-L) e}{1-\pi}-\frac{(2 \pi-1)}{1-\pi} \max \{\hat{R}(1-L) e-B, 0\}
$$

which implies the second equality in (A.12). From (A.12), it is straightforward to show that $\bar{q}(L, B)$ is increasing in $L$ for $\hat{R}(1-L) e>B$.

Step 5. Using steps 3 and 4, we now establish that there exists an equilibrium described in Lemmas 2 and 3 with $q<1$, and we show that the allocation of consumption and $q$ is unique conditional on $q<1$. Note that $q \geq 1 / \hat{R}$, since if $q<1 / \hat{R}$, then the solution to (A.7) admits $L=1$, but this implies from (A.12) that $q=\infty$ which is a contradiction. To characterize the solution to (A.7), we consider the case for which the solution admits $B>\hat{R}(1-L) e$ and the case for which the solution admits $B \leq \hat{R}(1-L) e$. We can show that the former case can only apply if $B>\bar{B}$, and the solution is characterized as in Lemma 2 . The latter case can only apply if $B \leq \bar{B}$, and the solution is characterized as in Lemma 3 .

Case 1. Suppose that the solution to (A.7) admits $B>\hat{R}(1-L) e$. If $q>1 / \hat{R}$, then the solution to (A.7) admits $L=0$, but this implies from (A.12) that $q=0$, which is a contradiction. Therefore, if the solution admits $B>\hat{R}(1-L) e$, it must be that $q=1 / \hat{R}$. Using this fact and substituting (3), (A.8), and (A.9) into (A.4) and (A.5), this implies that $c_{1}(0)=e$ and $c_{2}(1)=\hat{R} e$, which from (A.6) which binds this implies that $c_{2}(0)=c_{1}(1)=0$. From (A.12), this means that $L=\pi$, so that if $B>\hat{R}(1-L) e$, then $B>\bar{B}$. We are left to verify the optimality of the agent's choice of $L$ conditional on $q=1 / \hat{R}$ and $B>\bar{B}$. From (A.7), if $q=1 / \hat{R}$, then the agent is indifferent across all levels of $L$ conditional on $B \geq \hat{R}(1-L) e$. Moreover, conditional on $B \leq \hat{R}(1-L) e$, 
it is straightforward to see from (A.7) for $q=1 / \hat{R}$ that the maximal $L$ which sets $B=\hat{R}(1-L) e$ is optimal. Therefore, any value of $L$ which satisfies $B \geq \hat{R}(1-L) e$ is optimal, so that $L=\pi$ is a solution to the agent's problem conditional on $q=1 / \hat{R}$ and $B>\bar{B}$. This establishes that if $B>\bar{B}$, there exists an equilibrium as described in Lemma 2.

Case 2. Suppose that the solution to (A.7) admits $B \leq \hat{R}(1-L) e$. If it were the case that $B<\hat{R}(1-L) e$, then the first-order condition to (A.7), substituting in for $q$ using (A.12) and $c_{1}(0)=L e / \pi$ from step 4 is

$$
\pi u^{\prime}\left(\frac{L e}{\pi}\right)-(1-\pi) \rho \hat{R}\left(1-\frac{1}{\widetilde{q}(L, B) \hat{R}}\right) u^{\prime}\left(\hat{R}(1-L) e+\frac{L e}{\widetilde{q}(L, B)}\right)=0 .
$$

Note that the left-hand side of (A.16) is strictly decreasing in $L$. It therefore follows that the left-hand side of (A.16) is strictly negative for $L=1-B /(\hat{R} e)$, the maximum feasible value of $L$. However, if this is true, this violates the fact that $B>\hat{B}$. Therefore, if the solution to (A.7) admits $B \leq \hat{R}(1-L) e$, then it must be that $B=\hat{R}(1-L) e$ which implies from (A.15) that $c_{2}(0)=0$. Given (A.12), this implies from (A.13) and (A.14) that $c_{1}(0)=L e / \pi$ and $c_{2}(1)=\hat{R}(1-L) e /(1-\pi)$. Since $B=\hat{R}(1-L) e$, this implies by substitution the values of $q, c_{1}(0)$, and $c_{2}(1)$ described in Lemma 3 . We now verify that $1 / \hat{R} \leq q<1$. That $q<1$ is guaranteed by the fact that $B \geq \hat{B}$. In order that $q \geq 1 / \hat{R}$, it must be that $B \leq \bar{B}$. We are left to verify the optimality of the agent's choice of $L$ conditional on $q$ and $B \in(\hat{B}, \bar{B}]$. From our previous arguments, this choice of $L$ is optimal conditional on $B \leq \hat{R}(1-L) e$. Suppose instead that the agent prefers a value of $L$ which satisfies $B \geq \hat{R}(1-L) e$. Since $q>1 / \hat{R}$, then the solution to (A.7) admits the minimum value of $L$ so that $B=\hat{R}(1-L) e$. This establishes that the value of $L$ which satisfies $B=\hat{R}(1-L) e$ is optimal. Therefore, if $B \in(\hat{B}, \bar{B}]$, there exists an equilibrium as described in Lemma 3.

Since Case 1 only applies if $B>\bar{B}$ and case 2 only applies if $B \in(\hat{B}, \bar{B}]$, and the allocation and bond price are uniquely determined conditional on $B$ in both cases, it follows that the equilibrium allocation and price $q$ are unique conditional on $B$ and on $q<1$.

Step 6. To complete the argument, we must establish that conditional on $B>\hat{B}$, there does not exist an equilibrium with $q=1$. Consider the solution to (A.7) given that $q=1$. By the arguments in case 1 of step 5, it is not possible that the solution admits $B>\hat{R}(1-L) e$ since this would imply that $q=1 / \hat{R}<1$, which is a contradiction. Suppose that $B \leq \hat{R}(1-L) e$, so that

$$
L e \leq e-B / \hat{R} \text {. }
$$

Substituting (3), (A.10), and (A.11) into (A.4) and (A.5) taking into account that $q=1$, it follows that $c_{1}(0)=L e+B, c_{2}(0) / \hat{R}=(1-L) e-B / \hat{R}$, and $c_{1}(1)+c_{2}(1) / \hat{R} \geq$ $\left(c_{1}(1)+c_{2}(1)\right) / \hat{R}=(1-L) e+L e / \hat{R}$. Substituting these quantities into (A.6), this implies that

$$
B \leq \frac{1-\pi}{\pi} L e
$$


Equations (A.17) and (A.18) imply that $B \leq(\pi /(1-\pi)+1 / \hat{R})^{-1} e$, which contradicts (A.2). Therefore, there does not exist an equilibrium with $q=1$.

\section{Proof of Proposition 1}

Suppose the solution admitted $B \geq \bar{B}$ so that $q=1 / \hat{R}$. Consider the alternative policy $B=\bar{B}-\hat{R} \epsilon$ for $\epsilon>0$ arbitrarily small, so that from Lemma 3 , the perturbed value of $c_{1}(0)$ increases by $\epsilon / \pi$ and the perturbed value of $c_{2}(1)$ decreases by $\hat{R} \epsilon /(1-\pi)$. The change in welfare from such a perturbation has the same sign as

$$
u^{\prime}\left(c_{1}(0)\right)-\rho \hat{R} u^{\prime}\left(c_{2}(1)\right)>0,
$$

where the strict inequality follows from the fact that $c_{1}(0)=e<c_{1}^{E}(0)$ and $c_{2}(1)=$ $\hat{R} e>c_{2}^{E}$ (1) given (13). Since the solution admits $B<\bar{B}$, it cannot be that $q=1 / \hat{R}$ by the arguments in case 1 of step 5 in the proof of Lemmas 2 and 3.

Suppose that Condition 1 holds. Using (13), this implies that

$$
\pi u^{\prime}\left(c_{1}^{E}(0)\right)-(1-\pi) \rho \hat{R}\left(1-\frac{1}{\hat{R}} \frac{c_{2}^{E}(1)}{c_{1}^{E}(0)}\right) u^{\prime}\left(c_{2}^{E}(1)\right)>0 .
$$

Given (A.3), this means that $(1-\pi) c_{2}^{E}(1)>\hat{B}$, so that by Lemma 3 the competitive equilibrium for $B=(1-\pi) c_{2}^{E}(1)$ sustains the efficient allocation.

\section{References}

Albanesi, Stefania and Christopher Sleet (2006). "Dynamic Optimal Taxation with Private Information." Review of Economic Studies, 73, 1-30.

Ales, Laurence and Pricila Maziero (2009). "Non-Exclusive Dynamic Contracts, Competition, and the Limits of Insurance." Working paper, University of Pennsylvania.

Allen, Franklin and Douglas M. Gale (2004). "Financial Intermediaries and Markets." Econometrica, $72,1023-1061$.

Attanasio, Orazio and Victor Rios-Rull (2000). "Consumption Smoothing in Island Economies: Can Public Insurance Reduce Welfare?” European Economic Review, 44, 1225-1258.

Barro, Robert (1974). “Are Government Bonds Net Wealth?” Journal of Political Economy, 82, $1095-1117$.

Bassetto, Marco and Narayana Kocherlakota (2004). "On the Irrelevance of Government Debt when Taxes are Distortionary.” Journal of Monetary Economics, 51, 299-304.

Bisin, Alberto and Adriano Rampini (2006). "Exclusive Contracts and the Institution of Bankruptcy." Economic Theory, 27, 277-304.

Caballero, Ricardo and Arvind Krishnamurthy (2006). "Bubbles and Capital Flow Volatility: Causes and Risk Management." Journal of Monetary Economics, 53, 35-53.

Diamond, Douglas W. (1997). "Liquidity, Banks, and Markets." Journal of Political Economy, 105, 928-956.

Diamond, Douglas W. and Philip H. Dybvig (1983). "Bank Runs, Liquidity, and Deposit Insurance." Journal of Political Economy, 91, 401-419.

Farhi, Emmanuel, Mikhail Golosov, and Aleh Tsyvinski (2009). "A Theory of Liquidity and Regulation of Financial Intermediation.” Review of Economic Studies, 76, 973-992. 
Geanakoplos, John and Herakles Polemarchakis (1986). "Existence, Regularity, and Constrained Suboptimality of Competitive Allocations When the Asset Market Is Incomplete." In Essays in Honor of Kenneth J. Arrow: Uncertainty, Information, and Communication (Vol. 3), edited by W. Heller, R. Starr, and D. Starrett. Cambridge University Press, pp. 65-95.

Geanakoplos, John and Herakles Polemarchakis (2008). "Pareto Improving Taxes." Journal of Mathematical Economics, 44, 682-696.

Golosov, Mikhail and Aleh Tsyvinski (2007). "Optimal Taxation with Endogenous Insurance Markets." Quarterly Journal of Economics, 122, 487-534.

Greenwald, Bruce C. and Joseph E. Stiglitz (1986). "Externalities in Economies with Imperfect Information and Incomplete Markets." Quarterly Journal of Economics, 101, 229-264.

Holmstrom, Bengt and Jean Tirole (1998). "Private and Public Supply of Liquidity." Journal of Political Economy, 106, 1-40.

Jacklin, Charles J. (1987). "Demand Deposits, Trading Restrictions, and Risk Sharing." In Contractual Arrangements for Intertemporal Trade, edited by E. Prescott and N. Wallace. University of Minnesota Press, pp. 26-47.

Kocherlakota, Narayana (2007). "Money and Bonds: An Equivalence Theorem.” Working paper, Federal Reserve Bank of Minneapolis.

Kocherlakota, Narayana (2009). "Bursting Bubbles: Consequences and Cures." Working paper, Federal Reserve Bank of Minneapolis.

Woodford, Michael (1990). "Public Debt as Private Liquidity." American Economic Review, 80(2), 383-388. 